\title{
Comparative Assessment of Blood Pressure, Random Blood Sugar and Addiction Status among Security Staffs and Scavengers in an Indian Medical College Hospital
}

\author{
Abhishek Ghosh*, Debjyoti Halder and Keshab Mukhopadhyay \\ Department of Pharmacology, College of Medicine and JNM hospital, \\ Kalyani, Nadia, West Bengal, India \\ *Corresponding author
}

\section{Keywords}

Diabetes mellitus, hypertension, prevalence, staffs, medical college.

Article Info

Accepted:

14 September 2016 Available Online:

10 October 2016

\section{A B S T R A C T}

Incidence of hypertension and diabetes mellitus in India are increasing every year. It is very important to diagnose and treat hypertension and diabetes for preventing adverse cardiologic, renal and nervous system diseases. There is dearth of studies about prevalence of hypertension and diabetes among the security staffs and scavengers of a medical institute. This was a cross sectional observational unicentric study. Total 40 scavengers and 84 security staffs were included in the Study. After they gave consent, following data were collected like Blood pressure, Random blood sugar, Addiction history, Drug history. More than $50 \%$ of the staffs had smoking habit. $6.45 \%$ staffs were hypertensive and $3.23 \%$ staffs were diabetic. Blood sugar and blood pressure among the security staffs and scavengers were well controlled. There was no significant difference among mean blood pressure among 2 groups of staffs. Significant difference was found among mean of random blood sugar among 2 groups of staffs, higher in security staffs. Addiction of smoking was quite high among the staffs. Prevalence of hypertension and diabetes mellitus among the staffs were lower than that of general population.

\section{Introduction}

Hypertension is an independent predictor of cardiovascular disease and cerebrovascular events affecting nearly a quarter of the adult population worldwide. The Joint National Committee on Prevention, Detection, Evaluation, and Treatment of High Blood Pressure defines hypertension as blood pressure $>140 / 90 \mathrm{mmHg}$. Persons with systolic blood pressure of $120-139 \mathrm{~mm} \mathrm{Hg}$ or diastolic blood pressure of $80-89 \mathrm{~mm} \mathrm{Hg}$, are defined as having "prehypertension"
(Shetty et al., 2012). The prevalence of hypertension ranges from $20-40 \%$ in urban adults and $12-17 \%$ among rural adults. The number of people with hypertension is projected to increase from 118 million in 2000 to 214 million in 2025, with nearly equal numbers of men and women (Reddy, 2009; Midha et al., 2013).

Although hypertension has been well studied, there is dearth of data on the prevalence and risk factors for hypertension 
among security staffs and scavengers of medical institutions in India.

China is the diabetic capital of the world and India is very close second. WHO defines diabetes mellitus as fasting blood sugar> $126 \mathrm{mg} / \mathrm{dl}$ or 2 hour post prandial blood sugar $>200 \mathrm{mg} / \mathrm{dl}$. It is predicted that by 2030 diabetes mellitus may afflict up to 79.4 million individuals in India (Kaveeshwar et al., 2014).

In a study from Raichur Institute of Medical Sciences, out of 163 participants, prevalence of hypertension was $11.7 \%$, and $9.2 \%$ of staff had blood pressure in pre-hypertension range (Javali et al., 2015) in a Brazilian study, hypertension prevalence was $26 \%$ (Mion et al., 2015).

In a study among hospital staffs at Shiraz (Iran), the prevalence of pre hypertension and hypertension was $37.0 \%$ and $8.6 \%$ respectively. Only $6 \%$ of hypertensive staff were on anti-hypertensive pharmacological treatment. Among the treated patients, BP was under control in 35\% of staffs (Sahibi et al., 2010).

As we know the security staffs and scavengers are mostly from lower socioeconomic group and addiction is a common problem in persons from lower socio economic group. Addiction also is a risk factor for developing hypertension. So the aim of this study is to assess prevalence of hypertension and diabetes among security persons and scavengers of a tertiary care teaching hospital of eastern India and whether addiction status is correlated with hypertension and diabetes.

\section{Materials and Methods}

\section{Primary objective}

To find out the prevalence of hypertension, high blood glucose and addiction status among security staffs and scavengers in a tertiary care teaching hospital in Kalyani, West Bengal.

\section{Secondary objectives}

To assess whether there is difference of these parameters among two groups.

To assess whether addiction has correlation with development of hypertension and diabetes among these staffs.

This was a cross sectional observational unicentric study. Study began after getting clearance from Institutional Ethics Committee. Security staffs and scavengers of College of Medicine \& JNM hospital, Kalyani were provided with the protocol and their consent for participation in the study were asked for. Total 40 scavengers and 84 security staffs were included in the study after obtaining their consent.

After they gave consent, following data were collected

1. Age

2. Sex

3. Monthly family income

4. Blood pressure

5. Random blood sugar

6. Addiction history

7. Drug history

To measure the blood pressure an aneroid sphygmomanometer were used. It was ensured that no smoking or caffeine ingestion half an hour prior to the checking of their blood pressure. A cuff bladder encircling at least $80 \%$ of the arm circumference was applied to the nondominant arm. The disappearance of phase V Korotkoff sounds was taken as the diastolic reading. The mean of three readings recorded 2 min apart, was taken. 
Random blood sugar was tested, as well as routine urine examination was done to detect glycosuria. The staffs were asked to bring medicine OPD ticket of this hospital, where advice for doing random blood sugar and routine urine examination was written. They had done those tests from the central laboratory of the medical college hospital.

Necessary Statistical analysis was done after obtaining the results. Collected data will be checked for completeness, analyzed and presented using tables and figures. Computer software called SPSS version 20 will be used for analysis.

\section{Results and Discussion}

Total 84 security staffs and 40 scavengers were included in this study. All the security staffs were male, whereas among scavengers, 6 female and 34 male persons were included.

Regarding the addiction status among staffs, 50 security persons out of $84(59.52 \%)$ had habit of tobacco exposure, may be in form of smoking, or by khaini, or both. 6 pesrons (7.14\%) among them were taking alcohol also.

Among the scavengers, 20 persons out of 40 $(50 \%)$ had habit of tobacco exposure, either by smoking, or by khaini, or both. 9 persons $(22.5 \%)$ were taking regular alcohol. 4 persons were both smoker and alcoholic.

The study found that Blood pressure of all the staffs was below $140 / 90 \mathrm{~m}$ of $\mathrm{Hg}$, i.e., nobody had hypertension as per JNC 8 guideline. But, the study found that 5 security staffs and 3 scavenger staffs were taking antihypertensive drugs. So prevalence of hypertension among the staffs was (8/124 $\mathrm{X} 100=6.45 \%$ ). Also 3 security staffs and 1 scavenger staff was taking antidiabetic drugs, so prevalence of diabetes mellitus among the staffs was $(4 / 124 \times 100=3.23 \%)$.

Mean Blood pressure was measured for all the staffs. Average mean blood pressure of 84 security staffs were $90.96 \mathrm{~mm}$ of $\mathrm{Hg}$, with standard deviation of 5.27. Among the 40 scavengers, average mean blood pressure was $90.16 \mathrm{~mm}$ of $\mathrm{Hg}$, with standard deviation of 7.68 .

Independent sample $\mathrm{t}$ test was done to compare the means, and it revealed $\mathrm{p}$ value of 0.496 , with standard error of difference 1.18. So, the difference of mean BP among 2 groups of staffs were not significant.

Random blood sugar was measured in all the staffs. Mean of the random sugar of 84 security staffs was $96.69 \mathrm{mg} / \mathrm{dl}$, with standard deviation of 12.82 and standard error of mean 1.4. Mean of random blood sugar among 40 scavengers was found to be $91.75 \mathrm{mg} / \mathrm{dl}$, with standard deviation of 11.34 and standard error of mean 1.79.

Independent sample $\mathrm{t}$ test was done to compare the means of the 2 groups, and it revealed $p$ value of 0.04 , with standard error of difference 2.38. So, the difference of mean blood sugar among 2 groups of staffs was significant.

Now, while comparing the mean BP among smoker and non smoker of each group of staffs, we found that average mean BP of 50 security staffs (who had smoking habit) was $90.81 \mathrm{~mm}$ of $\mathrm{Hg}$. Independent sample $\mathrm{t}$ test was performed for comparison of means and it revealed $p$ value of 0.71 . So the difference of mean BP among smoker and non smoker security staffs was not significant.

Study also found the mean of random blood sugar of 50 security staffs with smoking habit was $98.36 \mathrm{mg} / \mathrm{dl}$. The mean of random 
blood sugar of 34 security staffs without smoking habit was $93.03 \mathrm{mg} / \mathrm{dl}$. Independent sample $t$ test was performed for comparison of means and it revealed $p$ value of 0.053 . So the difference of mean of random blood sugar among smoker and non smoker security staffs was not significant.

We found that average mean BP of 20 scavenger staffs (who had smoking habit) was $92.62 \mathrm{~mm}$ of $\mathrm{Hg}$, with standard error of mean 1.56 and average mean BP of 20 scavenger staffs (who are non smoker) was $87.7 \mathrm{~mm}$ of $\mathrm{Hg}$, with standard error of mean 1.73. Independent sample $t$ test was performed for comparison of means and it revealed $\mathrm{p}$ value of 0.04 . So the difference of mean BP among smoker and non smoker scavenger staffs was significant.

Study also found the mean of random blood sugar of 20 scavenger staffs with smoking habit was $91.45 \mathrm{mg} / \mathrm{dl}$ and mean of random blood sugar of 20 scavenger staffs without smoking habit was $92.05 \mathrm{mg} / \mathrm{dl}$ with standard error of mean 2.49. Independent sample $t$ test was performed for comparison of means and it revealed $p$ value of 0.87 . So the difference of mean of random blood sugar among smoker and non smoker scavenger staffs was not significant.

In this study, our aim was to detect prevalence of hypertension and diabetes mellitus among the security staffs and scavengers in a medical college hospital and whether addiction status has any correlation with the development of hypertension and diabetes mellitus.

The study did not find any staffs having blood pressure in the hypertensive range ,i.e., above $140 / 90 \mathrm{~mm}$ of $\mathrm{Hg}$ and no staff also had random blood sugar in the diabetic range, i.e., above $200 \mathrm{mg} / \mathrm{dl}$. But out of 84 staffs, 8 staffs were known hypertensive and taking medicine for that and 4 staffs were known diabetic (type II) and were taking antidiabetic drugs regularly. So, the prevalence of hypertension was less than the average prevalence of these 2 diseases in India, as almost $20 \%$ Urban Indian population and $10 \%$ or rural Indian population are hypertensive.

If we take reference from other previous studies, mostly done abroad, we found higher prevalence of hypertension than the results from our study.

In a study from Malaysia, overall prevalence of type 2 diabetes mellitus was $12.8 \%$. among 189 hospital staffs. ${ }^{8}$ In a study from Chennai involving 2600 subjects, Hypertension was present in $20 \%$ subjects. Age, body mass index, smoking, serum cholesterol and triglycerides were found to be strongly associated with hypertension (Mohan et al., 2007).

In our study, difference of mean blood sugar among 2 groups of staffs were significant (mean of blood sugar was less in scavengers) but difference of mean blood pressure was not significant among 2 groups. The difference in blood sugar among 2 groups may be due to difference in sample size in 2 groups.

More than half of the security staffs and half of the scavenger staffs had smoking habit. Some of the workers also take khaini, alcohol. Their addiction status probably results from the stressful life they have to lead for earning.

But result from this study showed that smoking habit does not significantly increase risk of hypertension alone. Out of 8 hypertensive staffs, 5 were smoker and 3 were non-smoker. Out of 4 diabetic staffs, none were smoker only 1 staff had habit of alcohol intake. 
While we compared the mean BP and random blood sugar among smoker and non smoker staffs in each group, we found that only difference of mean blood pressure among smoker and non smoker scavenger staffs was significant. Also, neither the difference of mean blood pressure, nor the difference of mean of random blood sugar among smoker and non-smoker security staffs was significant.

Table.1 Demographic data of 2 groups

\begin{tabular}{|l|l|l|}
\hline & Average age (years) & $\begin{array}{l}\text { Average monthly } \\
\text { family income } \\
\text { (rupees) }\end{array}$ \\
\hline Security staffs & 37.98 & 7238 \\
\hline Scavenger staffs & 32.92 & 6600 \\
\hline
\end{tabular}

Table.2 Independent sample t test for comparison of mean BP and blood sugar among 2 groups of staffs

\begin{tabular}{|c|c|c|c|c|c|}
\hline & \multicolumn{4}{|c|}{ t-test for Equality of Means } \\
\hline & & $\begin{array}{c}\text { Significance } \\
\text { (2-tailed) }\end{array}$ & $\begin{array}{c}\text { Mean } \\
\text { Difference }\end{array}$ & $\begin{array}{l}\text { Std. Error } \\
\text { Difference }\end{array}$ & $\begin{array}{c}95 \% \\
\text { Confidence } \\
\text { Interval of the } \\
\text { Difference }\end{array}$ \\
\hline $\begin{array}{l}\text { Random } \\
\text { sugar }\end{array}$ & $\begin{array}{l}\text { Equal variances } \\
\text { assumed }\end{array}$ & $\begin{array}{l}.040 \\
.496\end{array}$ & $\begin{array}{r}4.94048 \\
.80596\end{array}$ & $\begin{array}{l}2.37619 \\
1.17968\end{array}$ & $\begin{array}{r}.23658 \\
-1.52933\end{array}$ \\
\hline Mean BP & $\begin{array}{l}\text { Equal variances } \\
\text { assumed }\end{array}$ & & & & \\
\hline
\end{tabular}

Fig.1 Addiction status of the staffs of the hospital

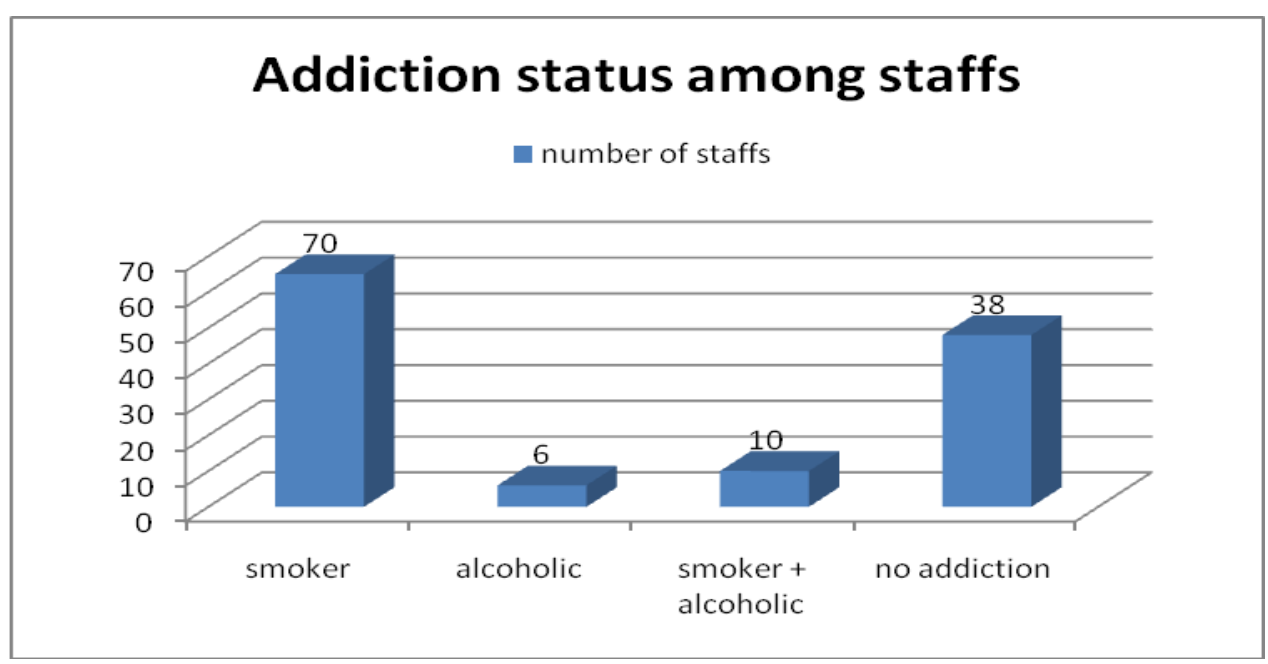


So from the study result, cannot come to conclusion that smoking definitely increases the mean blood pressure and blood sugar among the security and scavenger staffs of this hospital, as for increasing BP, other factors like food intake, lifestyle, stress factor are also responsible.

But in a study on prevalence of prehypertension and hypertension among doctors of the same institution (College of medicine and JNM hospital, Kalyani) done last year as ICMR project showed that $14.82 \%$ of the doctors had hypertension and $60.49 \%$ had prehypertension and smoking habit significantly increased development of hypertension and prehypertension among the doctors (Ghosh et al., 2016).

As the study involving the health status of security and scavenger staffs of medical teaching institutes in India are lacking, few more studies are required to understand their health status overall and thus it will help to motivate to implement healthy lifestyle to avoid development of hypertension and diabetes in future.

In conclusion, blood sugar and blood pressure among the security staffs and scavengers were well controlled. Addiction of smoking was quite high among the staffs. Prevalence of hypertension and diabetes mellitus among the staffs were lower than that of general population. There was no significant difference among mean blood pressure among 2 groups of staffs. Significant difference was found among mean of random blood sugar among 2 groups of staffs, higher in security staffs. Smoking habit did not affect the mean Blood pressure of the security staffs significantly, but among the scavengers, smokers had significantly higher mean BP than the non smokers. Smoking habit and status of random blood sugar among the staffs did not show positive correlation.

\section{Acknowledgement}

This study was a part of ICMR STS 2016 project. The protocol was approved by ICMR this year. Report is submitted in August 2016.

\section{References}

Ghosh, A., Mukhopadhya, K., Bera, R., Dasgupta, R. 2016. Prevalence of hypertension and prehypertension among doctors of different specialities in a tertiary care teaching hospital in Eastern India and its correlation with body mass index. Int. J. Med. Sci. Public Health, 5: 709-713.

Javali, R., Kirte, R., Muddaraddi, R. 2015. Prevalence of hypertension and its risk factors among staff of Raichur Institute of Medical Sciences, Raichur. Int. J. Med. Sci. Public Health, [cited December 10, 2015]; 3(12): 14701473.

Kaveeshwar, S.A.,' Cornwall, J. 2014. The current state of diabetes mellitus in India, Australas. Med. J., 7(1): 45-48.

Midha, T., Nath, B., Kumari, R., Rao, Y.K., Pandey, U. 2013. Prevalence of hypertension in India: a meta analysis, World J. Meta-Anal., 1(2): 83-89.

Mion, Jr. Decio, Pierin Angela, M.G., Bambirra Alberto, P., Assunção Jorge, H., Monteiro Juliana, M., Chinen Roberta, Y. et al. 2004. Hypertension in employees of a University General Hospital. Rev. Hosp. Clin., [Internet]. [cited 2015 Dec 10] 59(6): 329-336

Mohan, V., Deepa, M., Farooq, S., Datta, M., Deepa, R. 2007. Prevalence, awareness and control of hypertension in Chennai-The Chennai Urban Rural Epidemiology Study (CURES-52). J. Assoc. Physicians India, 55: 326-332.

Prem Kumar, B., Hayati, K.S., Rampal, L. 2014. Prevalence of type 2 diabetes 
mellitus and its associated factors among a public university staff in selangor. Int. J. Public Health and Clin. Sci., Vol. 1:No. 1, 118-30.

Reddy, K.S. 2009. Regional case studiesIndia. Nestle Nutr Workshop Ser Pediatr Program, 63: 15-24; discussion 41-16, 259-268.
Sahibi, L., Vahidi, R.G., Mousavi, S.H. 2010. Prevalence of Hypertension and Associated Variables in Hospital Staff in Iran, Acta Med. Sal., 39(1): 6-13.

Shetty, S.S., Nayak, A. 2012. Prevalence of prehypertension amongst medical students in coastal karnataka, J. Evol. Med. Dent. Sci., Volume 1, Issue 6, 975-980.

\section{How to cite this article:}

Abhishek Ghosh, Debjyoti Halder and Keshab Mukhopadhyay. 2016. Comparative Assessment of Blood Pressure, Random Blood Sugar and Addiction Status among Security Staffs and Scavengers in an Indian Medical College Hospital. Int.J.Curr.Microbiol.App.Sci. 5(10): 294300. doi: http://dx.doi.org/10.20546/ijcmas.2016.510.033 